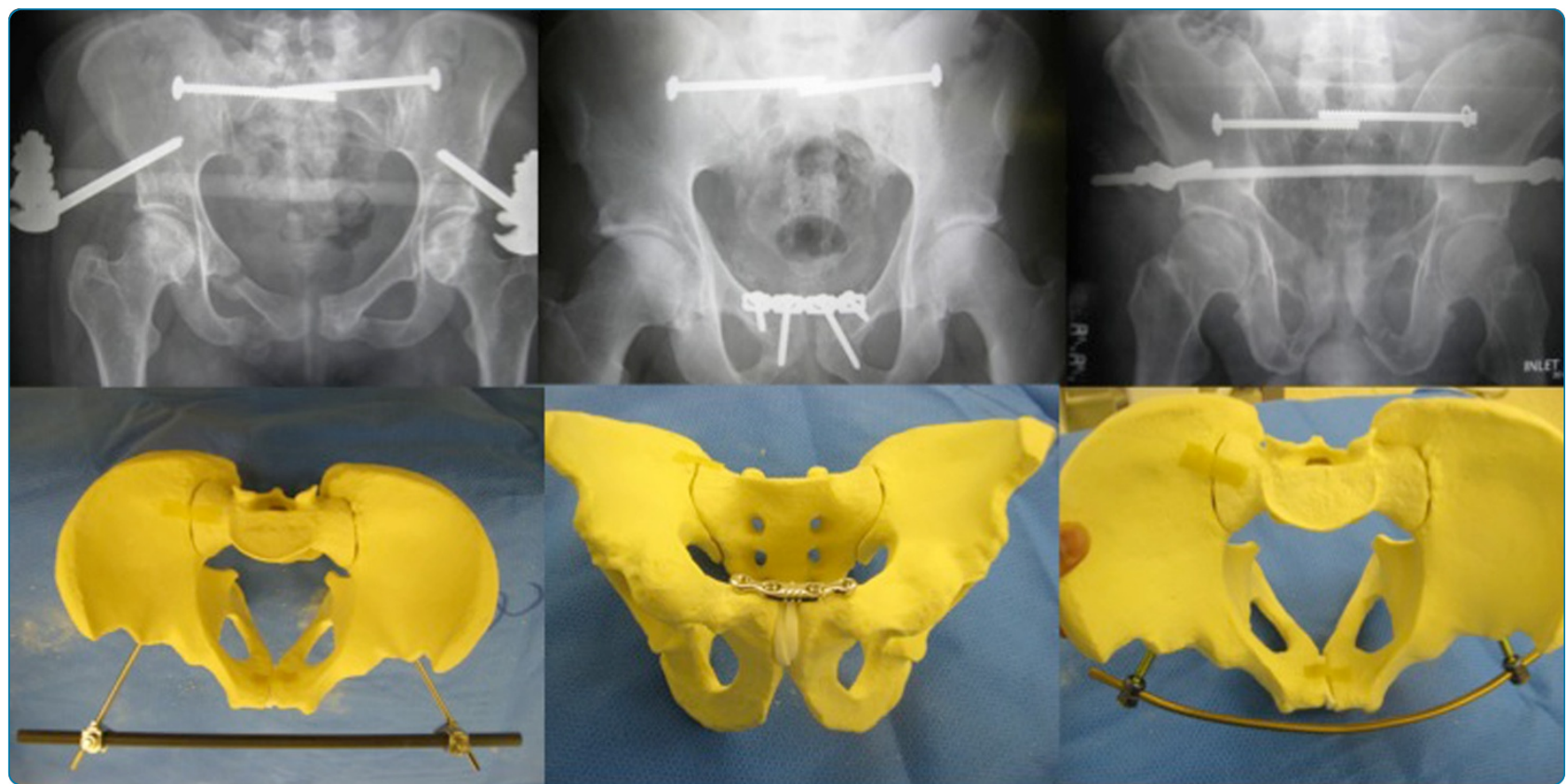

Biomechanical stability of a supra-acetabular pedicle screw Internal Fixation device (INFIX) vs External Fixation and plates for vertically unstable pelvic fractures

Vigdorchik et al. 


\title{
Biomechanical stability of a supra-acetabular pedicle screw Internal Fixation device (INFIX) vs External Fixation and plates for vertically unstable pelvic fractures
}

\author{
Jonathan M Vigdorchik ${ }^{1+}$, Amanda O Esquivel ${ }^{2+}$, Xin $\mathrm{Jin}^{3+}$, King H Yang ${ }^{3+}$, Ndidi A Onwudiwe ${ }^{1+}$
} and Rahul Vaidya ${ }^{1 * \dagger}$

\begin{abstract}
Background: We have recently developed a subcutaneous anterior pelvic fixation technique (INFIX). This internal fixator permits patients to sit, roll over in bed and lie on their sides without the cumbersome external appliances or their complications. The purpose of this study was to evaluate the biomechanical stability of this novel supraacetabular pedicle screw internal fixation construct (INFIX) and compare it to standard internal fixation and external fixation techniques in a single stance pelvic fracture model.

Methods: Nine synthetic pelves with a simulated anterior posterior compression type III injury were placed into three groups (External Fixator, INFIX and Internal Fixation). Displacement, total axial stiffness, and the stiffness at the pubic symphysis and SI joint were calculated. Displacement and stiffness were compared by ANOVA with a Bonferroni adjustment for multiple comparisons

Results: The mean displacement at the pubic symphysis was 20,9 and $0.8 \mathrm{~mm}$ for external fixation, INFIX and internal fixation, respectively. Plate fixation was significantly stiffer than the INFIX and external Fixator $(P=0.01)$ at the symphysis pubis. The INFIX device was significantly stiffer than external fixation ( $P=0.017)$ at the symphysis pubis. There was no significant difference in SI joint displacement between any of the groups.

Conclusions: Anterior plate fixation is stiffer than both the INFIX and external fixation in single stance pelvic fracture model. The INFIX was stiffer than external fixation for both overall axial stiffness, and stiffness at the pubic symphysis. Combined with the presumed benefit of minimizing the complications associated with external fixation, the INFIX may be a more preferable option for temporary anterior pelvic fixation in situations where external fixation may have otherwise been used.
\end{abstract}

\section{Background}

External fixation for unstable pelvic fractures is effective in resuscitation and reduces pelvic volume, minimizes motion between disrupted fracture surfaces or joints, allows tamponade of ongoing venous bleeding and is a fairly quick procedure [1-5]. Side to side rolling of patients, sitting and laying prone is limited with the use of pelvic external fixators. In addition the pins are always at risk for pin tract infection and require constant nursing surveillance

\footnotetext{
*Correspondence: RVaidya@dmc.org

${ }^{\dagger}$ Equal contributors

'Detroit Receiving Hospital, 4201 St Antoine St, Detroit, Ml 48201, USA Full list of author information is available at the end of the article
}

particularly in obese patients [6]. We have recently developed a technique using the already established principles of anterior external fixation but placed subcutaneously. This technique basically involves two pedicle screws, one in each ilium placed in the supra-acetabular area connected to each other via a subcutaneous $6 \mathrm{~mm}$ rod tunnelled just below the belly crease, in an area called the bikini area [7]. This internal fixator (INFIX) permits patients to sit, roll over in bed and lie on their sides without the cumbersome external appliances or their complications [8] (Figure 1). The purpose of this study was to evaluate the biomechanical stability of this novel supra-acetabular pedicle screw internal 

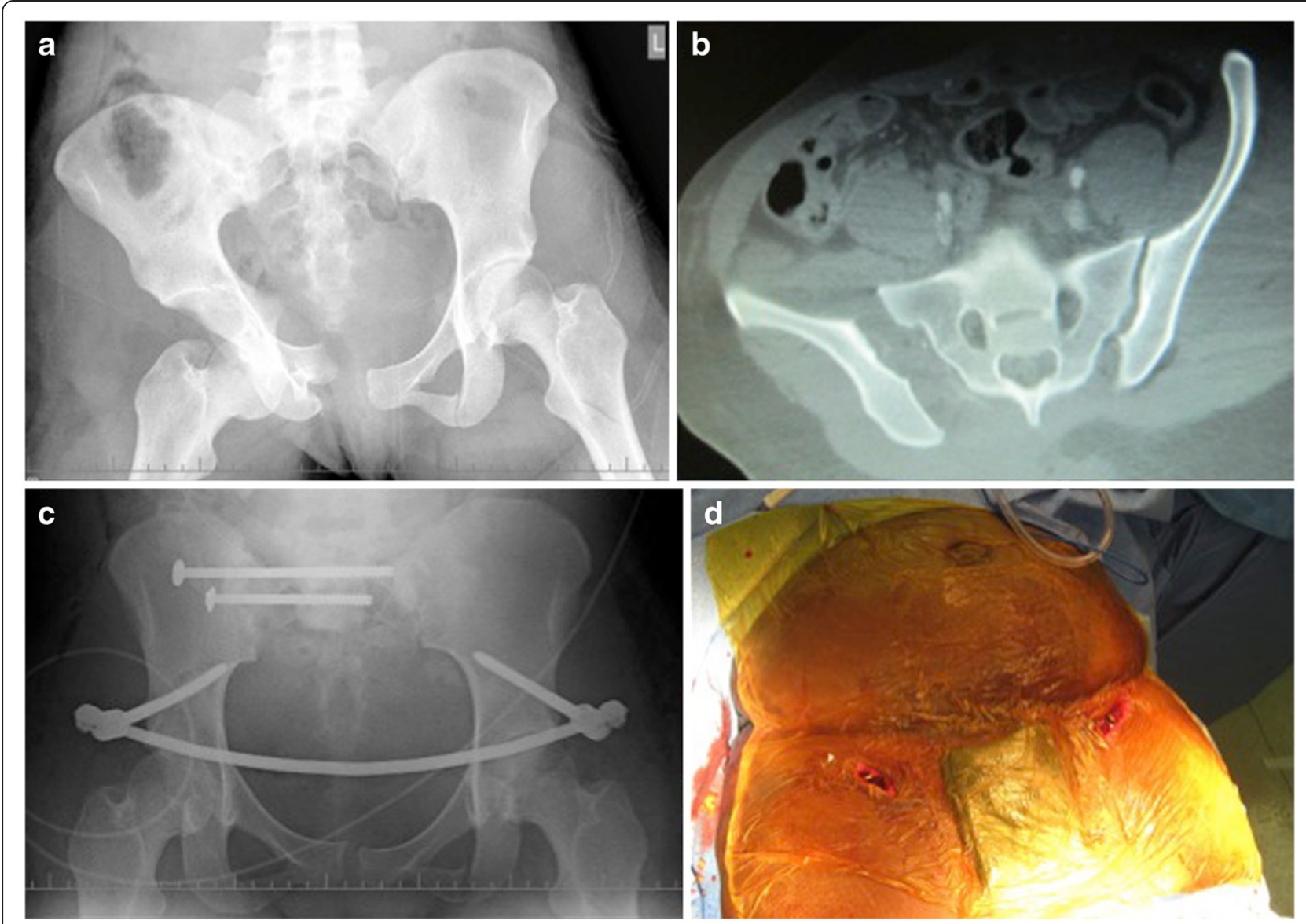

Figure 1 Case Example a) Xray APC 3 Pelvic injury b) CT scan showing opening of Right SI joint c) Fixation with posterior SI screws and INFIX anteriorly d) Incisions for insertion of INFIX before closure.

fixation construct (INFIX) and compare it to standard internal fixation and external fixation techniques in a single stance pelvic fracture model.

\section{Methods}

Nine synthetic pelves (\#1301-21, Sawbones, Vashon, WA) with a simulated anterior posterior compression (APC) type III (Figure 2a) injury were placed into the following groups:

1. INFIX $(\mathrm{n}=3)$, by $7.0 \mathrm{~mm} \times 80 \mathrm{~mm}$ titanium polyaxial pedicle screws and $6.0 \mathrm{~mm}$ stiff titanium rod (Click'X Pedicle Screw System, Synthes, West Chester, PA) (Figure 2b,c)

2. Internal fixation $(\mathrm{n}=3)$, by $3.5 \mathrm{~mm}$ 4-hole pubic symphysis plate (Synthes, West Chester, PA)

3. External fixation $(n=3)$, by 2 supra-acetabular $5.0 \mathrm{~mm}$ Schanz pins, with an $11 \mathrm{~mm}$ carbon fiber rod (Synthes, West Chester, PA)

A single orthopaedic surgeon prepared all the specimens. A custom device was attached to the sacrum and connected to the load cell of a uni-axial servohydraulic testing device (Instron Corp, Canton, MA) through a ball and socket joint which was allowed to articulate freely (Figure 3).

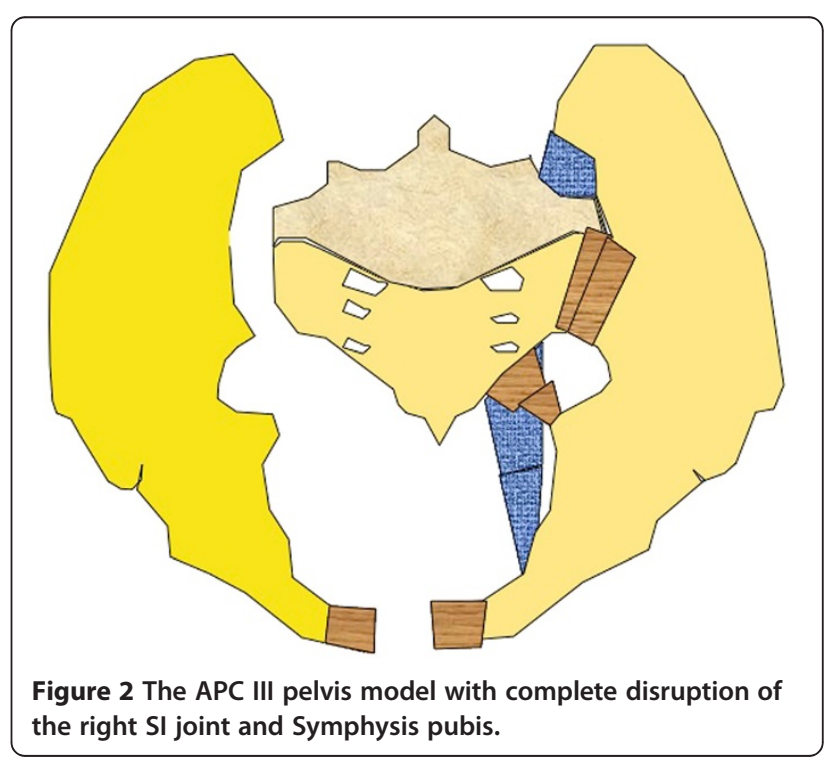




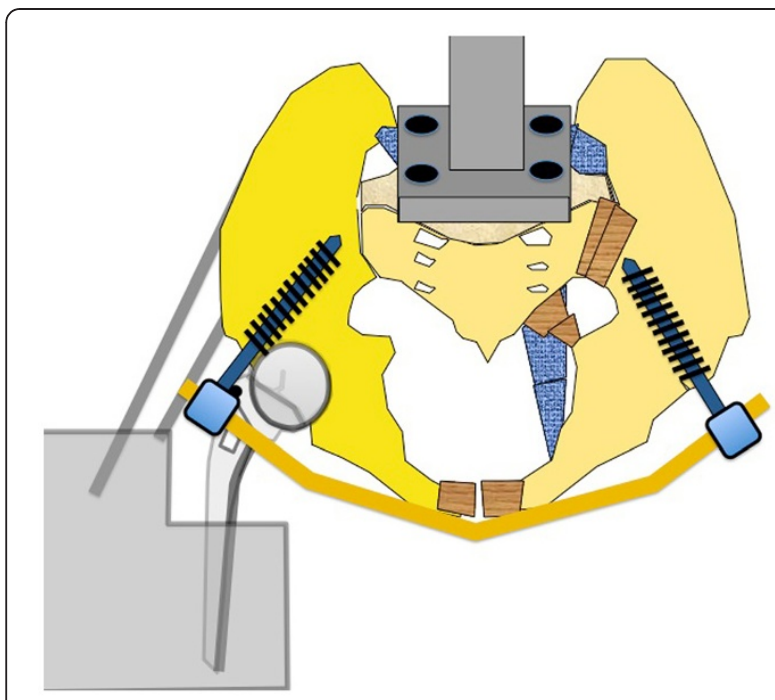

Figure 3 The pelvis mounted on the apparatus with the INFIX Apparatus. The sacrum is attached to the Instron Device and the separated hemi pelvis is fixed with wire cables to simulate the abductor muscles with the Hip prosthesis potted to simulate the single stance gait.

A unipolar hemiarthroplasty prosthesis was potted at 15 degrees adduction, to simulate a single leg stance. Each pelvis was tilted 45 degrees anteriorly and the femoral head was in contact with the acetabulum. A cable and pulley system was used to simulate abductor muscle pull on the pelvis. The abductor cables were loaded prior to each test cycle at $10 \mathrm{~N}$. A compressive load was applied through the sacrum up to $200 \mathrm{~N}$ or $15 \mathrm{~mm}$ of displacement. Markers were placed at the pubic symphysis and sacroiliac (SI) joint and high-speed video was recorded at 125 frames/sec to measure displacement. Displacement, total axial stiffness, and the stiffness at the pubic symphysis and SI joint were calculated $[9,10]$. Displacement and stiffness were compared by ANOVA with a Bonferroni adjustment for multiple comparisons.

\section{Results}

The mean displacement at the pubic symphysis was 20, 9 and $0.8 \mathrm{~mm}$ for external fixation, INFIX and internal fixation, respectively (Figure 4). This difference was statistically significant for the INFIX device when compared to external fixation $(P=0.017)$. There was also a significant difference between internal fixation and external fixation $(P=0.01)$. There was no significant difference in SI joint displacement between any of the groups. In terms of stiffness $(\mathrm{N} / \mathrm{m})$, internal fixation was significantly $(P<0.05)$ stiffer than either construct at the pubic symphysis. There was no significant difference between the stiffness of the INFIX and the external fixation device. Stiffness of the INFIX and external fixation

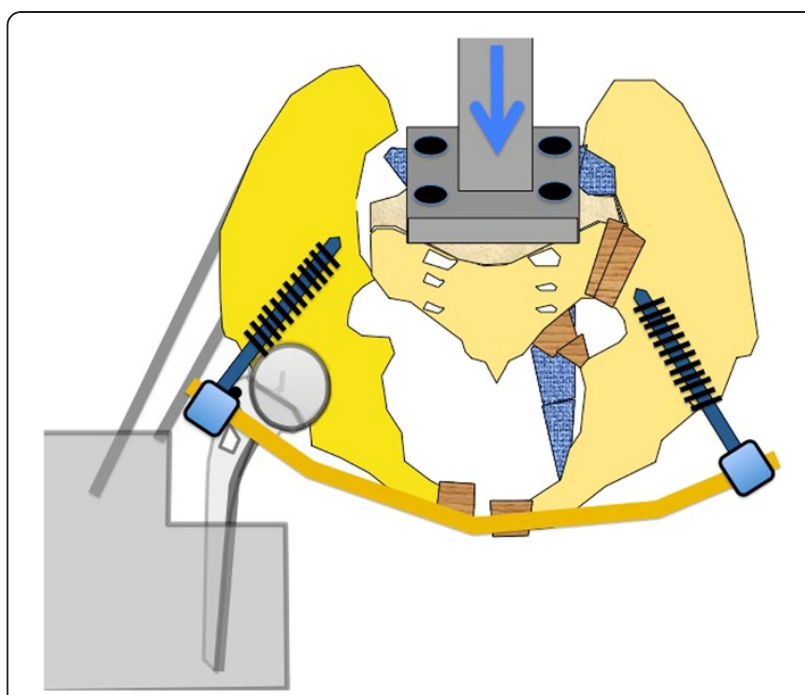

Figure 4 Loading of the construct with the INSTRON $200 \mathrm{~N}$ or $15 \mathrm{~mm}$.

constructs were then compared as a percentage of internal fixation stiffness (Figure 5). Although, not significantly different, the INFIX system was almost twice as stiff as external fixation (10.5\% vs $5.6 \%)$ in overall stiffness and also stiffer at the pubic symphysis $(1.1 \%$ vs $0.3 \%$ ) the area of most clinical importance for this type of fixation. At the superior portion of the anterior SI joint, external fixation was stiffer than the INFIX $(9.7 \%$ vs 6\%) (Figures 6 and 7).

\section{Discussion}

The purpose of this investigation was to compare the relative stiffness of three anterior pelvic fixation

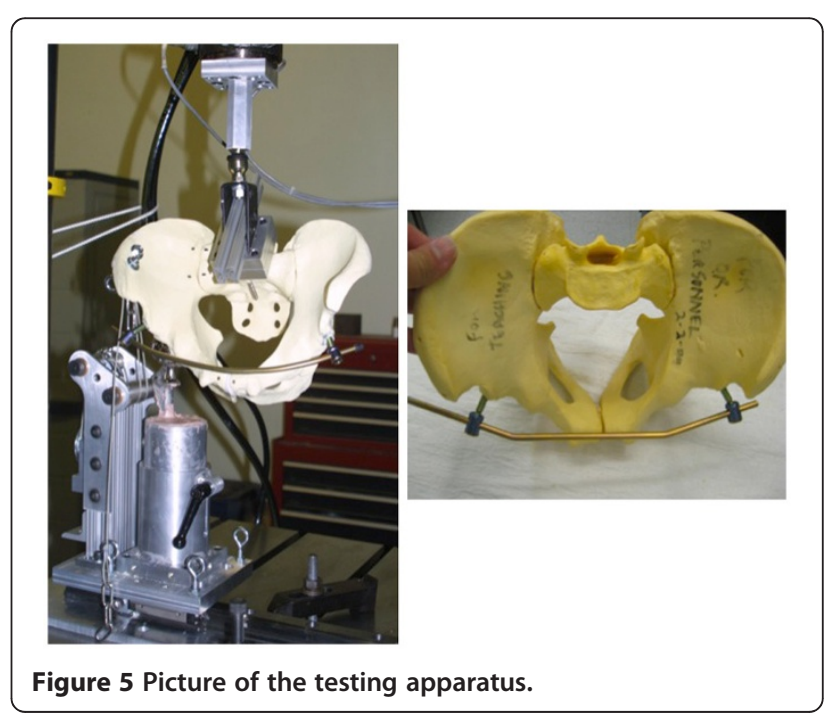




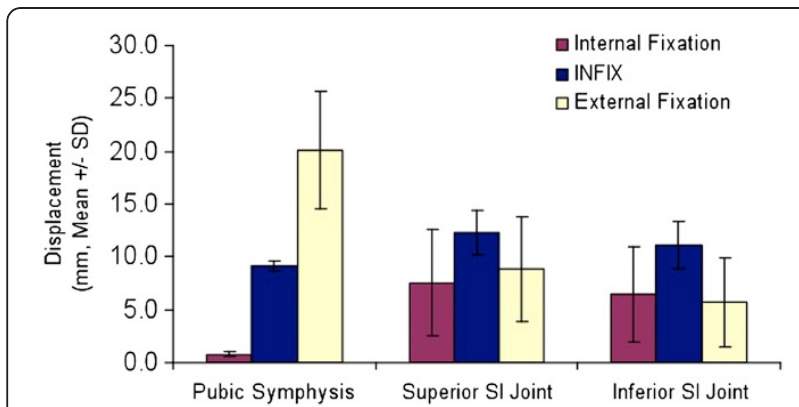

Figure 6 Mean displacement of each construct under axial loading.

constructs. A significant difference was observed between the constructs for pubic symphysis displacement. We found that the symphyseal plate $(3.5 \mathrm{~mm}$ 4-hole pubic symphysis plate Synthes, West Chester, PA) was significantly stiffer than the INFIX or the external fixator (2 supra-acetabular $5.0 \mathrm{~mm}$ Schanz pins, with an $11 \mathrm{~mm}$ carbon fiber rod Synthes, West Chester, PA) with this single leg stance pelvic model at the symphysis pubis $(\mathrm{p}<0.05)$. The INFIX construct allowed less than half the displacement at the symphysis pubis ( 9 vs $20 \mathrm{~mm}$ ) when compared to the external fixator $(\mathrm{p}<017)$. When we compared stiffness there was a trend for the INFIX to be stiffer at the symphysis pubis verses the external fixator but this was not significant. The external fixator had slightly less displacement at the SI joint verses the INFIX (not significant). There was no significant difference in stiffness between any of the threee constructs at the SI joint. This is consistent with previous studies that have indicated that there is wide variability between fixation devices at this point [10,11]. Many previous studies have been performed testing internal fixation techniques for pelvic ring injuries with single or double leg stance. We chose a single-leg stance model, as this was the most unstable scenario, with greater shear, bending and rotational forces than a double-leg stance and has been postulated to be more relevant to the clinical application [12,13]. Other

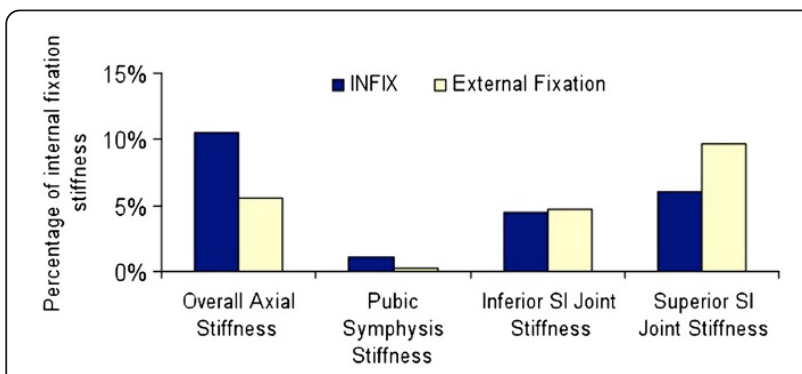

Figure 7 Comparison of mean stiffness of the INFIX and external fixation to internal fixation. studies have used strain gauges, inclinometers, linear voltage transducers, or electromagnetic motion sensors to measure displacements, rotations, and 3-dimensional motions [9-12,14-19]. We chose highspeed video because it allowed us to evaluate in realtime the complex motions across the pelvis, and gave us an accurate (up to $0.8 \mathrm{~mm}$ ) detection of displacement to measure the stiffness of each construct. It is difficult to extrapolate data across studies as many different fixation methods and loading techniques were examined: transiliac plates, 1, 2, or 3 sacroiliac screws, transiliac rods, and tension band plates have all been examined in single [12,13,20-22] and double leg stance $[9,14,16-18,23]$ models with varying loads, from $250-2000 N$. Different injury patterns were also tested, with or without stabilization of the anterior pelvis $[13,14,16,17]$. Between studies and between constructs, no significant differences in stability were shown. However, all methods of fixation are inferior to the intact pelvis $[9,16]$. A limitation to this study was the small sample size for each construct; however, there was a significant difference observed in pubic symphysis gapping. We used a synthetic pelvic model which has been used in several pelvic biomechanic studies because there is uniform material for fixation and testing $[2,11]$. Although cadaver pelvises are optimal it would be difficult to compare the two pin external fixator and the INFIX construct in the same model due to the same location of screw insertion and in different models because of the variability between specimens. Unstable type C or APC III injuries are recommended to have both anterior and posterior fixation (24). However, this biomechanical test model represents the worst-case scenario in terms of force transmission that would be seen clinically and provides a repeatable, previously used biomechanical testing method to compare the stiffness of the constructs.

\section{Conclusion}

The data show that both the INFIX and the external fixator are significantly weaker than internal fixation at the pubic symphysis. The INFIX was stiffer than external fixation for both overall axial stiffness, and stiffness at the pubic symphysis, the area of most clinical importance for this type of fixation. Combined with the presumed benefit of minimizing the complications associated with external fixation, the INFIX may be a more preferable option for temporary anterior pelvic fixation in situations where external fixation may have otherwise been used. Future improvements to the design may help to increase the stability of the construct. 


\section{Abbreviations}

INFIX: Internal fixator; APC: Anterior posterior compression; ANOVA: Analysis of variance; SI Joint: Sacroiliac joint.

\section{Competing interests}

Dr. R Vaidya Corresponding author is developing an FDA approved product with Stryker Corporation which has not been manufactured yet or produced. That is not the device in this study as these are just common pedicle screws and rods that are in any spine set. No other author has any competing interests.

\section{Authors' contributions}

Role of each author - JV - First author, Participated in developing the study design, implanted the specimens, worked on writing the paper, and performed testing - AE - Second author participated in developing the study design, worked on writing the paper, testing and result evaluation - XJ: Helped with study design, testing, result evaluation and statistics - KY: Helped with study design, testing, result evaluation and statistics - NO: Participated in writing the manuscript, formatting, statistics checks and submitting of the manuscript RV: Corresponding Author, Participated in. All authors read and approved the final manuscript.

\section{Author details}

'Detroit Receiving Hospital, 4201 St Antoine St, Detroit, MI 48201, USA.

2Providence Hospital and Medical Centers, 16001 West 9 Mile Road Southfield, MI, USA. 'Wayne State University, 540 E Canfield St, Detroit, MI, USA

Received: 17 February 2012 Accepted: 26 September 2012 Published: 27 September 2012

\section{References}

1. Gardner MJ, Kendoff D, Ostermeier S, Citak M, Hüfner T, Krettek C, Nork SE: Sacroiliac joint compression using an anterior pelvic compressor: a mechanical study in synthetic bone. J Orthop Trauma 2007, 21(7):435-441.

2. Gardner MJ, Nork SE: Stabilization of unstable pelvic fractures with supraacetabular compression external fixation. J Orthop Trauma 2007, 21(4):269273.

3. Grimm MR, Vrahas MS, Thomas KA: Pressure-volume characteristics of the intact and disrupted pelvic retroperitoneum. J Trauma 1998, 44(3):454-459.

4. Kregor PJ, Routt ML Jr: Unstable pelvic ring disruptions in unstable patients. Injury 1999, 30(Suppl 2):B19-B28.

5. Riemer BL, Butterfield SL, Diamond DL, Young JC, Raves JJ, Cottington E, Kislan K: Acute mortality associated with injuries to the pelvic ring: the role of early patient mobilization and external fixation. J Trauma 1993, 35(5):671-675. discussion 676-677.

6. Hupel TM, McKee MD, Waddell JP, Schemitsch EH: Primary external fixation of rotationally unstable pelvic fractures in obese patients J Trauma 1998, 45(1):111-115.

7. Vaidya R, Colen R, Vigdorchik J, Tonnos F, Sethi A: Treatment of unstable pelvic ring injuries with an internal anterior fixator and posterior fixation: initial clinical series. J Orthop Trauma 2012, 26(1):1-8.

8. Vaidya R, Kubiak EN, Bergin PF, Dombroski DG, Critchlow RJ, Sethi A, Starr AJ: Complications of anterior subcutaneous internal fixation for unstable pelvis fractures: a Multicenter Study. Clin Orthop Relat Res 2012, Epub ahead of print

9. Varga E, Hearn T, Powell J, Tile M: Effects of method of internal fixation of symphyseal disruptions on stability of the pelvic ring. Injury 1995, 26:75-80.

10. Yinger K, Scalise J, Olson SA, Bay BK, Finkemeier CG: Biomechanical comparison of posterior pelvic ring fixation. J Orthop Trauma 2003, 17(7):481-487.

11. Ponsen KJ, Joosse P, Van Dijke GA, Snijders CJ: External fixation of the pelvic ring: an experimental study on the role of pin diameter, pin position, and parasymphyseal fixator pins. Acta Orthop 2007, 78(5):648-653.

12. Pohlemann $T$, Angst M, Schneider E, Ganz R, Tscherne H: Fixation of transforaminal sacrum fractures: a biomechanical study. J Orthop Trauma 1993, 7(2):107-117.

13. Shaw JA, Mino DE, Werner FW, Murray DG: Posterior stabilization of pelvic fractures by use of threaded compression rods. Case reports and mechanical testing. Clin Orthop Relat Res 1985, 192:240-254.
14. Comstock CP, van der Meulen MC, Goodman SB: Biomechanical comparison of posterior internal fixation techniques for unstable pelvic fractures. J Orthop Trauma 1996, 10:517-522.

15. Leighton RK, Waddell JP, Bray TJ, Bray TJ, Hapman MW, Simpson L, Martin $\mathrm{RB}$, Sharkey NA: Biomechanical testing of new and old fixation devices for vertical shear fractures of the pelvis. J Orthop Trauma 1991, 5:313-317.

16. Simonian PT, Routt C Jr, Harrington RM, Tencer AF: Internal fixation for the transforaminal sacral fracture. Clin Orthop Relat Res 1996, 323:202-209.

17. Simonian PT, Routt ML Jr, Harrington RM, Mayo KA, Tencer AF: Biomechanical simulation of the anteroposterior compression injury of the pelvis. An understanding of instability and fixation. Clin Orthop Relat Res 1994, 309:245-256.

18. Simonian PT, Routt ML Jr, Harrington RM, Tencer AF: Internal fixation of the unstable anterior pelvic ring: a biomechanical comparison of standard plating techniques and the retrograde medullary superior pubic ramus screw. J Orthop Trauma 1994, 8(6):476-482.

19. Van Zwienen CM, van den Bosch EW, Snijders CJ, Kleinrensink GJ, van Vugt $A B$ : Biomechanical comparison of sacroiliac screw techniques for unstable pelvic ring fractures. J Orthop Trauma 2004, 18:589-595.

20. Dujardin FH, Roussignol X, Hossenbaccus M, Thomine JM: Experimental study of the sacroiliac joint micromotion in pelvic disruption. $J$ Orthop Trauma 2002, 16:99-103.

21. MacAvoy MC, McClellan RT, Goodman SB, Chien CR, Allen WA, van de Meulen MC: Stability of open-book pelvic fractures using a new biomechanical model of single-limb stance. J Orthop Trauma 1997 11:590-593.

22. Pohlemann T, Culemann U, Tscherne H: Comparative biomechanical studies of internal stabilization of trans-foraminal sacrum fractures. Orthopade 1992, 21(6):413-421.

23. Rubash HE, Brown TD, Nelson DD, Mears DC: Comparative mechanical performances of some new devices for fixation of unstable pelvic ring fractures. Med Biol Eng Comput 1983, 21:657-663.

doi:10.1186/1749-799X-7-31

Cite this article as: Vigdorchik et al.: Biomechanical stability of a supraacetabular pedicle screw Internal Fixation device (INFIX) vs External Fixation and plates for vertically unstable pelvic fractures. Journal of Orthopaedic Surgery and Research 2012 7:31.

\section{Submit your next manuscript to BioMed Central and take full advantage of:}

- Convenient online submission

- Thorough peer review

- No space constraints or color figure charges

- Immediate publication on acceptance

- Inclusion in PubMed, CAS, Scopus and Google Scholar

- Research which is freely available for redistribution 